\title{
Improved Droop Control with DC Grid Resonance Damping Capability
}

\author{
Agustí Egea-Àlvarez $*$, Sajjad Fekriasl ${ }^{\dagger}$, Eduardo Prieto-Araujo ${ }^{*}$ \\ *University of Strathclyde, Electrical and Electric Engineering Department, 204 George Street, G1 1WX Glasgow UK \\ (agusti.egea@strath.ac.uk), ${ }^{\dagger} A B B, U K,{ }^{\ddagger} C I T C E A-U P C$, Spain
}

Keywords: Droop control, VSC-HVDC, Multiterminal systems, Offshore wind farm, Grid integration

\begin{abstract}
The concept of the so-called droop control has been widely discussed in the literature as the preferred controller for Voltage Source Converter for High Voltage Direct Current (VSC-HVDC) multiterminal and DC grid schemes. Droop control provides fast dynamic response and power-sharing between converter stations among other advantages but, as the controller is usually implemented as a merely proportional gain, the DC grid resonances damping is often very poor. This is because although the grids under study are DC, a broad range of high-frequency components and transient dynamics are inevitable in DC grids caused by long cables and switching to name a few. Conventional droops based on proportional gain are not able to handle such frequency-dependant issues of the DC grids. To improve the DC dynamic response, this paper presents a new droop controller where a DC resonance mitigation compensator is augmented to the conventional droop control that will result in an improved droop compensation by guaranteeing that power-sharing task will satisfactorily meet the desired damping requirements.
\end{abstract}

\section{Introduction}

In the recent years, the number of High Voltage Direct Current (HVDC) projects has raised substantially mainly because of the deployment of the Voltage Source Converter (VSC) technology for high voltage applications. VSC-HVDC compared to conventional HVDC or Line Commutated Converters (LCC), allows independent control of the active and reactive power, black start capability and bidirectional power flow control without voltage reversal among other advantages [1]. At the same time, the required HVDC substation footprint in VSC application is much less because of the reduced AC filtering stage.

One of the applications where VSC-HVDC has received great interest is the connection of offshore wind farms. For the distances higher than $150 \mathrm{~km}$, HVDC might present technical and economic advantages over HVAC lines [2]. Some offshore connected wind farms are already in operation [3] and more are planned. As these HVDC connected might be close to each other, the interconnection of the different HVDC transmission system has been suggested. The first interconnected systems that are likely to appear are so-called Multiterminal HVDC (MT-HVDC) schemes that have three or more electrical nodes without any electrical loop between them.

The voltage [4] and power control [5] of MT-HVDC systems have been widely addressed in the literature offering the droop control as the preferred voltage control technique [6]. The purpose of the droop control is to ensure an adequate power transmission and it should be decentralized so that the control law applied by an HVDC converter only depends on local measurements made by that converter whilst it does not need to rely on long-distance communications between different terminals. The droop controller is based on a proportional control law that regulates the DC voltage and provides power sharing between the different power converters. The cost to be paid to use of this simple control is a poor dynamic response. There are two main variations of the droop control: the powerbase droop and the current-based droop. The power baseddroop has the DC voltage as input and the power as the output and the current-based droop has the DC voltage as the input and the DC current as output. The design of the droop controller for HVDC applications has been addressed in for the current droop [7], [8] and in for the power [9].

This paper presents a modified droop controller where a leadlag filter is designed to be augmented in series to the traditional droop controller. This add-on high-pass filter improves the DC voltage dynamic response minimizing the DC overvoltage with a minor droop controller modification. The large and smallsignal modelling, design and a test case study are discussed and presented in this paper.

\section{Studied system}

The system under study is shown in Fig. 1. It is a three terminal MT-HVDC system where VSC1 is connected to an offshore wind farm and VSC2 and VSC3 are connected to two independent AC grids. Each wind farm is connected. In normal operation, the power flows from the offshore wind farm to the grid connected converters. The amount of power shared between the grid connected converters depends on interactions between the different grid side converter droop controllers. 


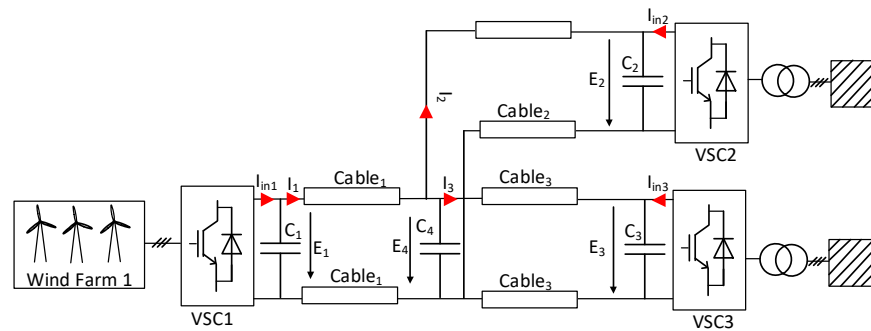

Figure 1: Studied three terminal MT-HVDC system

\section{MT-HVDC Modelling}

Here, both time and frequency domain models have been developed to design the augmented optimal DC droop controller.

\subsection{Converter model}

Modular Multilevel Converters (MMCs) is currently the most used converter structure for VSC-HVDC interconnectors. Here, an average model of MMC is used via expressing its internal energy as an equivalent capacitance to simplify the analysis which focus on the DC side dynamics.

\subsection{Cable model}

A standard approach to model the DC cables is the piequivalent model, but the research presented in [10] shows that the pi-equivalent model can lead to inaccurate results. In this paper, the improved model presented in [10] is used. This model takes into account the frequency dependency of the DC cable adding several RL in parallel. Fig. 2 shows an example of the suggested cable model.

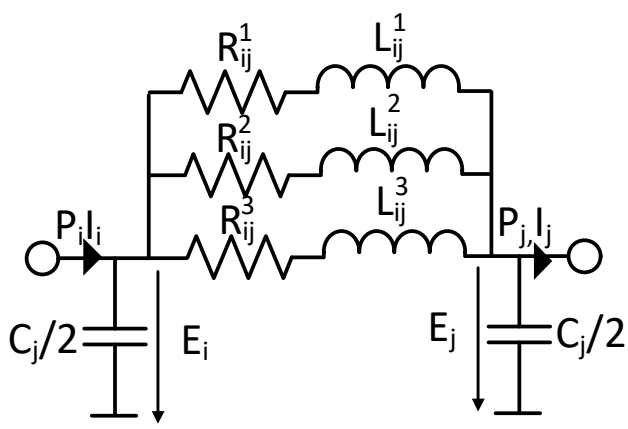

Figure 2: Model of the cable used for this study [10].

The equations associated with the cable model are

$$
\begin{gathered}
\frac{d E_{i}}{d t}=\frac{1}{c_{i}}\left(\frac{P_{i}}{E_{i}}-I_{i j}^{k}\right) \\
\frac{d E_{j}}{d t}=\frac{1}{c_{i}}\left(I_{i j}^{k}-\frac{P_{j}}{E_{j}}\right) \\
\frac{\mathrm{dI}_{\mathrm{ij}}^{\mathrm{k}}}{d t}=\frac{\mathrm{R}_{\mathrm{ij}}^{\mathrm{k}}}{\mathrm{L}_{\mathrm{ij}}^{\mathrm{k}}} \mathrm{I}_{\mathrm{ij}}+\frac{1}{\mathrm{~L}_{\mathrm{ij}}^{\mathrm{k}}} E_{\mathrm{i}}-\frac{\mathrm{R}_{\mathrm{ij}}^{\mathrm{k}}}{\mathrm{L}_{\mathrm{ij}}^{\mathrm{k}}} \mathrm{E}_{\mathrm{j}}
\end{gathered}
$$

where $E_{i}$ and $E_{j}$ are the voltages at the cable equivalent capacitors, $I_{i}, P_{i}$ and $\mathrm{I}_{\mathrm{j}}, P_{j}$ are the currents and powers at the cable terminals, $\mathrm{I}_{\mathrm{ij}}{ }^{\mathrm{k}}$ are the currents flowing through the branch $\mathrm{k}$ of the line $\mathrm{ij}, \mathrm{C}_{\mathrm{i}}$ and $\mathrm{C}_{\mathrm{j}}$ are the equivalent capacitance at each cable terminal and $\mathrm{L}_{\mathrm{ij}}{ }^{\mathrm{k}}$ and $\mathrm{R}_{\mathrm{ij}}{ }^{\mathrm{k}}$ are the inductance and resistance of the branch $\mathrm{k}$ of the line $\mathrm{ij}$. At the terminals where a converter is connected an extra capacitance $\mathrm{C}_{\mathrm{con}}$ is added. The subscript " $i$ " an " $j$ " refers to the cable terminal node and the superscript " $k$ " refers to each of the RL branches of the cable model.

\subsection{AC grid model}

The AC grid has been modelled with a Thévenin equivalent and the VSC is connected to the grid by means of an inductive coupling filter. A sketch of the analysed AC side can be seen in Figure 3.

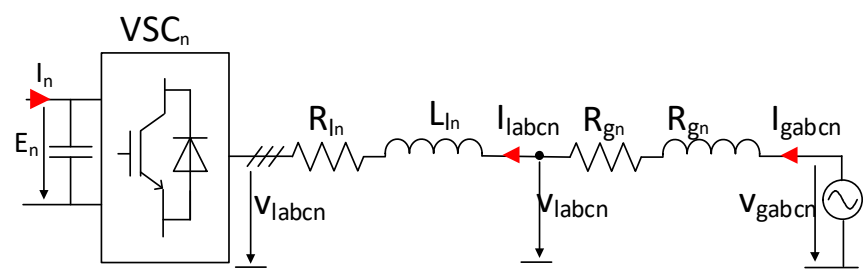

Figure 3: Converter AC side model

The equations of the AC system dynamics are:

$$
\begin{aligned}
& \frac{d i_{l q n}}{d t} L_{t n}=R_{t n} i_{l q n}-\omega L_{t n} i_{l d n}-v_{l q n}+v_{g q n} \\
& \frac{d i_{l d n}}{d t} L_{t n}=R_{t n} i_{l d n}+\omega L_{t n} i_{l q n}-v_{l d n}+v_{g d n}
\end{aligned}
$$

where $L_{t n}\left(L_{t n}=L_{l n}+L_{g n}\right)$ and $R_{t n}\left(R_{t n}=R_{l n}+R_{g n}\right)$ are the total system impedance, $\omega$ is the grid frequency and $v_{l n}$ and $v_{l g}$ are the converter and grid voltages, respectively. The subscript " $n$ " refers to the converter $n$ related variables.

\section{MT-HVDC Control}

The Grid Side Converter (GSC) exchanges the required power to keep the DC voltage in the converter terminals within the limits. The GSC converter is formed by the current control and the HVDC voltage controller.

\subsection{Grid Side Converter control}

The GSC control is implemented as a standard current dq-axis current controller and a PLL to provide the grid orientation [4]. The current control is implemented as two PI controllers $\left(\mathrm{K}_{\mathrm{iln}}\right)$ one for the q-component of the current $\left(\mathrm{i}_{\mathrm{qn}}\right)$ and another one for the d-component plus a decoupling term. 


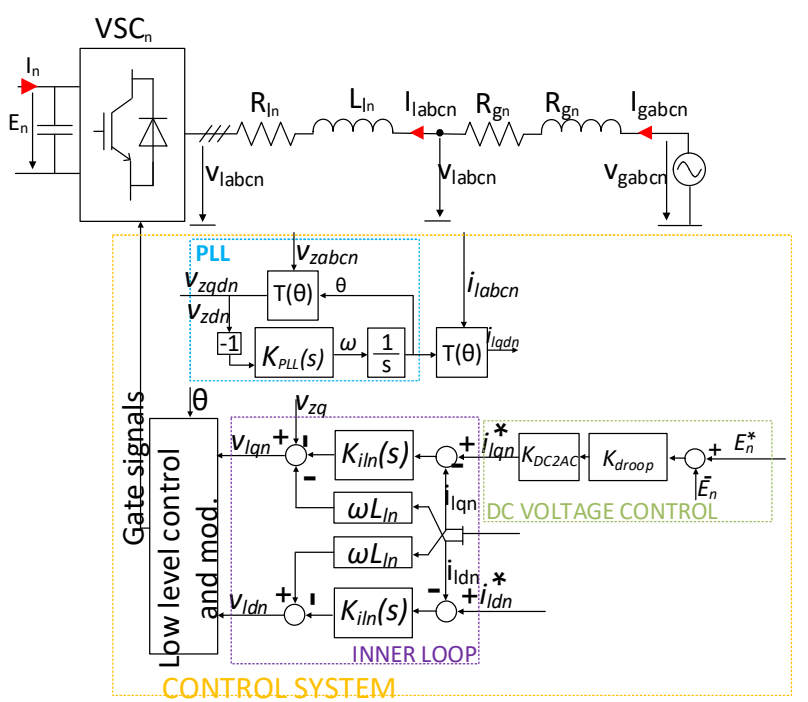

Figure 4: AC current control and DC voltage

$\mathrm{K}_{\mathrm{iln}}$ can be designed using the Internal Model Control technique [11] resulting the following controller

$$
K_{i l n}=\frac{k_{p i l n} s+K_{p i l n}}{s}
$$

where $K_{\text {pil }}$ is the proportional term and $K_{\text {iiln }}$ is the controller integral term and

$$
\begin{gathered}
k_{p i l n}=L_{l n} \tau_{i l n} \\
k_{i l n}=R_{l n} \tau_{i l n}
\end{gathered}
$$

where $\tau_{i l n}$ is the closed loop time constant of the desired controller response. This constant must be chosen considering converter physical restrictions. For this paper, $\tau_{i l n}=12 \mathrm{~ms}$ is considered.

\subsection{MT-HVDC voltage control and new suggested droop control}

The droop has been identified as the preferred controller for multiterminal HVDC systems. The basic implementation of the droop controller is

$$
I_{d c}=K_{d c 2 a c} \underbrace{\left(E_{n}-E_{n}^{*}\right) K_{\text {droopn }}}_{\text {Standard droop }}
$$

where $E_{n}$ is the DC link voltage at converter $\mathrm{n}, \mathrm{K}_{\mathrm{droopn}}$ is the droop controller gain and $\mathrm{K}_{\mathrm{dc} 2 \mathrm{ac}}$ is a constant factor to transform DC current into the AC side. Traditionally, the droop controller is designed to satisfy the steady-state power-sharing ensuring that the maximum overvoltage is not reached. In this paper a new droop controller to enhance the frequency response is suggested

$$
I_{d c}=K_{d c 2 a c} G_{f n}(s)=G_{f n}{ }^{\prime}(s) \underbrace{\left(E_{n}-E_{n}^{*}\right) K_{\text {droopn }}}_{\text {Standard droop }}
$$

where $G_{\mathrm{f}}(\mathrm{s})$ is a lead-lag filter where its transfer function is:

$$
G_{f n}(s)=K_{f n} \frac{s-Z_{f n}}{s-P_{f n}}
$$

The steps to design the filter are:

1) Choose the desired $K_{\text {droop }}$ according the powersharing and maximum overvoltage capability.

2) Run an optimization problem (see below paragraph) to calculate the most appropriate filter to mitigate the DC resonances.

3) Verity the controller dynamic requirements in the small signal and time domain model.

The optimization problem is based on $\mathrm{H}_{\infty}$ optimization. The conventional $\mathrm{H}_{\infty}$ control problem has a drawback in that it does not have any structure - for the same plant, depending on many design criteria, one can find different controllers with different orders. This makes $\mathrm{H}_{\infty}$ control of less interest to practical applications. Apkarian, Noll and Gahinet (The MathWorks [15]) have pioneered a novel approach to compute locally optimal controllers for the problem of $\mathrm{H} \infty$ optimization subject to both soft and hard design goals. Their research has been resulted in recent MATLAB functions, HINFSTRUCT and SYSTUNE, which are now available in the MATLAB Robust Control Toolbox. Both HINFSTRUCT and SYSTUNE formulate and solve the $\mathrm{H}_{\infty}$ control problem to find local optimal [16]-[17]. The mathematical principle underlying these tools is the $\mathrm{H}_{\infty}$-rationale based on non-smooth optimization solutions to the problem of $\mathrm{H} \infty$ optimization. In this paper, we have use SYSTUNE to design the three filter gains optimally by tuning fixed-structure droop control system.

\subsection{Model linearization}

To design the controller, a linear model is needed for which reason the model has been linearised and expressed in the state space form as

$$
\Delta \dot{x}_{\text {total }}=A_{\text {total }} \Delta x_{\text {total }}+B_{\text {total }} \Delta u_{\text {total }}
$$

where $\Delta x_{\text {total }}$ and $\Delta x_{\text {total }}$ are the vectors of states and inputs of the whole linearised system and $A_{\text {total }}$ and $B_{\text {total }}$ are the total system matrix and input matrixes of the total system respectively. The linearized model have been built based on [12] and [13]. Figure 5 shows the detailed linearized model for the VSC2 of the system presented in Section 2. The superscript "c" referrers tot the variables expressed in the converter frame.

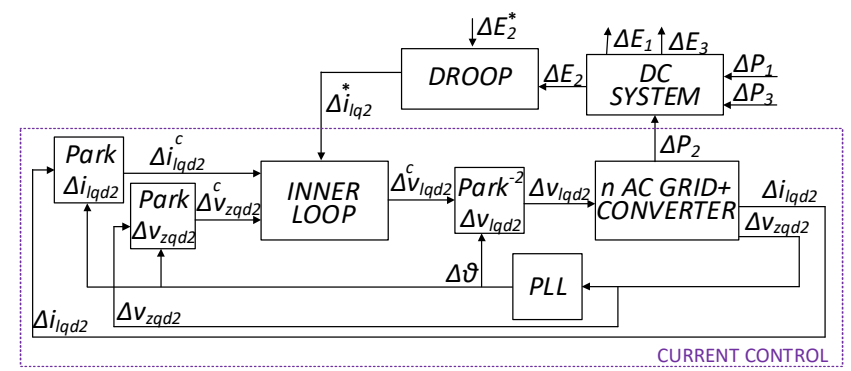

Figure 5: Detailed VSC1 converter control and interaction with the $\mathrm{AC}$ and $\mathrm{DC}$ system and the converter 


\section{Simulation results}

A study case is presented to show the design and the effectiveness of the proposed method. A time domain and a small signal model have been implemented in Simulink based on the system presented in Figure 1. The electrical parameters and the control parameters used for the design and simulations can be found in Table 1 and Table 2 respectively.

\begin{tabular}{|l|l|}
\hline Parameters & Value \\
\hline Grid SCR & 10 \\
\hline AC grid nominal voltage $[\mathrm{kV}]$ & 195 \\
\hline $\mathrm{L}_{\mathrm{n}}[\mathrm{pu}]$ & 0.1 \\
\hline $\mathrm{R}_{\mathrm{ln}}[\mathrm{pu}]$ & 0.01 \\
\hline $\mathrm{DC}$ system nominal voltage $[\mathrm{kV}]$ & 300 \\
\hline Converter nominal Power $[\mathrm{MVA}]$ & 300 \\
\hline $\mathrm{R}^{1}[\Omega / \mathrm{km}]$ & $1.1724 \cdot 10^{-1}$ \\
\hline $\mathrm{R}^{2}[\Omega / \mathrm{km}]$ & $8.2072 \cdot 10^{-2}$ \\
\hline $\mathrm{R}^{3}[\Omega / \mathrm{km}]$ & $1.1946 \cdot 10^{-2}$ \\
\hline $\mathrm{C}^{1}[\mathrm{~F} / \mathrm{km}]$ & $0.1983 \cdot 10^{-6}$ \\
\hline $\mathrm{C}_{\text {con }}[\mathrm{F} / \mathrm{km}]$ & $1.5000 \cdot 10^{-4}$ \\
\hline $\mathrm{L}^{1}[\mathrm{H} / \mathrm{km}]$ & $2.2851 \cdot 10^{-4}$ \\
\hline $\mathrm{L}^{2}[\mathrm{H} / \mathrm{km}]$ & $1.5522 \cdot 10^{-3}$ \\
\hline $\mathrm{L}^{3}[\mathrm{H} / \mathrm{km}]$ & $3.2942 \cdot 10^{-3}$ \\
\hline
\end{tabular}

Table 1: Electrical parameters used in the study case

\begin{tabular}{|l|l|}
\hline Controller gain parameters & Value \\
\hline $\begin{array}{l}\text { Current control time constant }\left(\tau_{\text {iln }}\right) \\
{[\mathrm{s}]}\end{array}$ & 0.012 \\
\hline $\mathrm{Z}_{\mathrm{f} 1}$ & -12.96 \\
\hline $\mathrm{P}_{\mathrm{z} 1}$ & -57.7388 \\
\hline $\mathrm{K}_{\mathrm{z} 1}$ & 0.4456 \\
\hline $\mathrm{Z}_{\mathrm{f} 2}$ & -16.80 \\
\hline $\mathrm{P}_{\mathrm{z} 2}$ & -72.02 \\
\hline $\mathrm{K}_{\mathrm{z} 2}$ & 0.4265 \\
\hline
\end{tabular}

Table 2: Control Parameters used in the study case

As first step, a $K_{\text {droop1 }}=K_{\text {droop } 2}=1 / 10 \mathrm{~A} / \mathrm{V}$ is selected for both power converters to satisfy the required power flow sharing. Once the droop constant is selected is possible to run the optimisation problem to calculate the most convenient $\mathrm{G}_{\mathrm{fl}}(\mathrm{s})$ and $\mathrm{G}_{\mathrm{f} 2}(\mathrm{~s})$. Figure 6a shows the singular value decomposition (SVD) of the system considering the VSC3 power as input (P1) and the VSC2 DC voltage (E2) as output for the MT-HVDC scheme using traditional droop control for different droop gains. In this figure, a high gain around $10-70 \mathrm{~Hz}$ can be seen leading to a potential overshoots and oscillations at that range of frequencies. Also, it can be observed that the overshoot is higher when the droop controller gain is bigger.
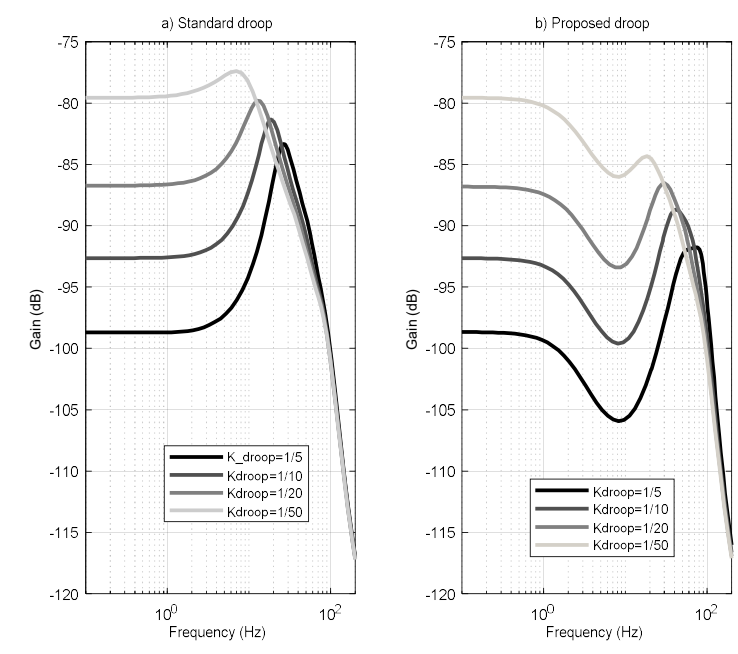

Figure 6: Singular value decomposition of the system considering the VSC3 power as input (P1) and the VSC2 DC voltage (E2) as output for the standard droop and the proposed droop controller

After running the optimization algorithm a suggested transfer function for $\mathrm{G}_{\mathrm{f1}}(\mathrm{s})$ and $\mathrm{g}_{\mathrm{f} 2}(\mathrm{~s})$ are obtained and their Bode plots are presented in Figure 7. As it can be observed, the optimized filters keep the DC gain at $-20 \mathrm{~dB}(0.1 \mathrm{~A} / \mathrm{V})$ but presents a highpass filter characteristics for frequencies above $5 \mathrm{~Hz}$. In this way, the potential oscillations that can occur at the area of 10$70 \mathrm{~Hz}$ can be mitigated. The SVD presented in Figure $6 \mathrm{~b}$ for different droops shows a reduction of these peaks. For the studied case of Kdroop=1/10 A/V the gain peak is reduced from $-84 \mathrm{~dB}$ to $-93 \mathrm{~dB}$.
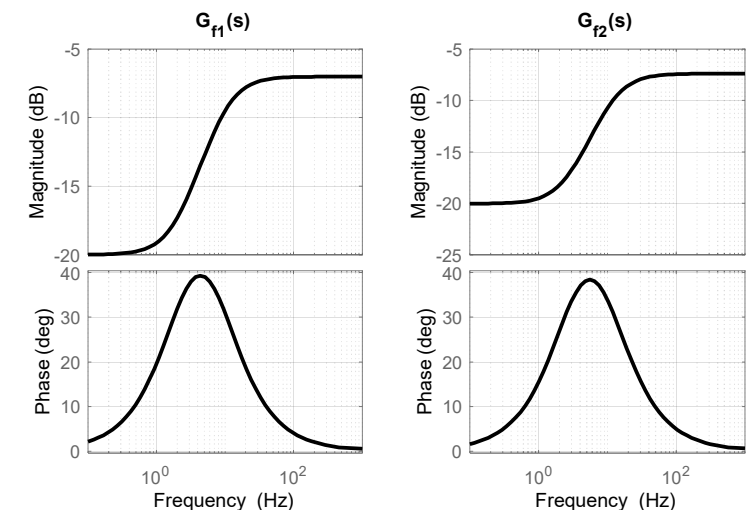

Figure 7: Bode diagram of Gf1(s) and Gf2(s)

In the time domain (some droop controller gain), this gain reduction can be seen as an improvement in the voltage overshoot and faster power response. Figure 8 and Figure 9 present the DC voltages and powers in front of a VSC1 (P1) power step change in the time instant $\mathrm{t}=2 \mathrm{~s}$ from $100 \mathrm{MW}$ to 200 MW for the standard droop and the proposed droop control. The overvoltage in the VSC2 and VSC 3 are reduced around $70 \%$ and VSC1 presents an overshoot improvement 
around 50\%. If the powers are analysed in Figure 9, the voltage improvement is due to the faster response of the DC injected power due to the increased sensitivity of the proposed droop controller at the frequencies where the overshoot occurs. It worth mention that the bandwidth of the current loop has been not modified.

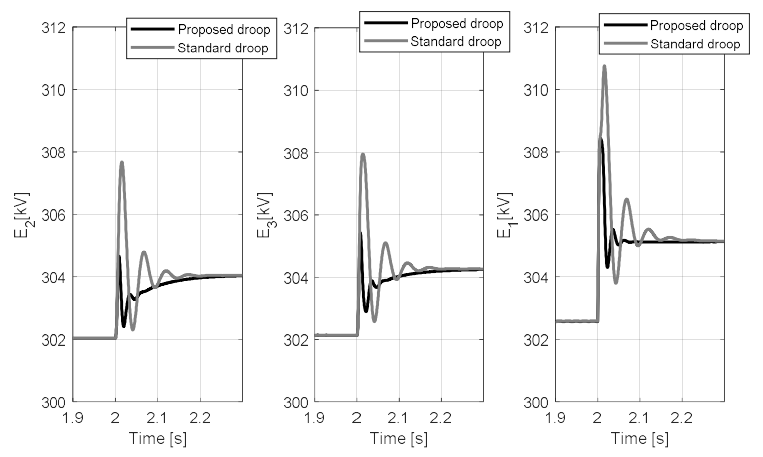

Figure 8: DC voltages E1, E2 and E3 in front of a VSC1 (P1) power step change for the standard and the proposed droop control
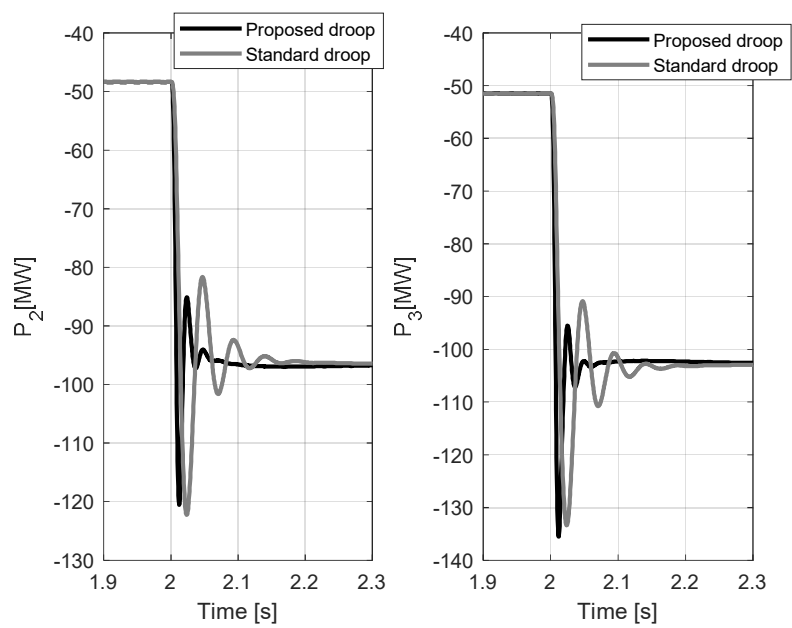

Figure 9: VSC1 and VSC2 DC power in front of a VSC1 (P1) power step change for the standard and the proposed droop control

\section{Conclusions}

An improved droop control structure with DC Grid resonance damping capability has been suggested, together with a complete methodology to design the controller. First, a generic model for a MT-HVDC network is detailed, including the DC grid and the converter dynamics. Then, a linear model is derived to be used during the controller tuning process, based on optimization techniques. The design methodology is applied to a three termianl DC grid, achieving an improved DC grid voltage profile, reducing the voltage oscillations importantly, maintaining the system and converter variables within its limits.

\section{Acknowledgment}

Agustí Egea-Àlvarez is a Lecturer of the Strathclyde Chancellor's Fellow programme. This work has been partially funded by the Spanish Ministry of Economy and Competitiveness under the Project ENE2015-67048-C4-1-R. This research was co-financed by the European Regional Development Fund (ERDF). Eduardo Prieto is a Lecturer of the Serra Húnter programme.

\section{References}

[1] D. Van Hertem, O. Gomis-Bellmunt and J. Liang, HVDC grids: for offshore and supergrid of the future, John Wiley \& Sons, 2016.

2] A. Kalair, N. Abas and N. Khan, "Comparative study of HVAC and HVDC transmission systems," Renewable and Sustainable Energy Reviews, vol. 59, pp. 16531675, 2016.

[3] A. Abdalrahman and E. Isabegovic, "DolWin1Challenges of connecting offshore wind farms," in ENERGYCON, 2016.

[4] T. K. Vrana, J. Beerten, R. Belmans, B. Fosso and Olav, "A classification of DC node voltage control methods for HVDC grids," Electric Power Systems Research, pp. 137-144, 2013.

[5] A. Egea-Alvarez, J. Beerten, D. Van Hertem and O. Gomis-Bellmunt, "Hierarchical power control of multiterminal HVDC grids," Electric Power Systems Research, vol. 121, pp. 207-215, 2015.

[6] L. $\mathrm{Xu}$ and L. Yao, "DC voltage control and power dispatch of a multi-terminal HVDC system for integrating large offshore wind farms," IET Renewable Power Generation, vol. 5, pp. 223-233, 2011.

[7] E. Prieto-Araujo, F. Bianchi, A. Junyent-Ferre and O. Gomis-Bellmunt, "Methodology for Droop Control Dynamic Analysis of Multiterminal VSC-HVDC Grids for Offshore Wind Farms," IEEE Transactions on Power Delivery, vol. 26, pp. 2476-2485, 2011.

[8] A. S. Abdel-Khalik, A. M. Massoud, E. A. A and S. Ahmed, "Optimum Power Transmission-Based Droop Control Design for Multi-Terminal HVDC of Offshore Wind Farms," IEEE Transactions on Power Systems, vol. 28, pp. 3401-3409, 2013.

[9] E. Prieto-Araujo, A. Egea-Alvarez, S. Fekriasl and O. Gomis-Bellmunt, "DC Voltage Droop Control Design for Multiterminal HVDC Systems Considering AC and DC Grid Dynamics," IEEE Transactions on Power Delivery, vol. 31, pp. 575-585, 2016.

[10] J. Beerten, d. Salvatore and J. Are Suul, "Frequencydependent cable modelling for small-signal stability analysis of VSC-HVDC systems," IET Generation, Transmission and Distribution, vol. 10, pp. 1370-1381, 2016.

[11] L. Harnefors and H. Nee, "Model-based current control of $\mathrm{AC}$ machines using the internal model control 
method," EEE Transactions on Industry Applications, vol. 34, pp. 133-141, 1998.

[12] L. Zhang, "Modeling and control of VSC-HVDC links connected to weak AC systems," KTH, 2010.

[13] A. Egea-Alvarez, S. Fekriasl, F. Hassan and O. GomisBellmunt, "Advanced vector control for voltage source converters connected to weak grids," Transactions on Power Systems, vol. 6, pp. 3072-3081, 2015.

[14] X. Li, Z. Yuan, F. J. Y. Wang, T. Liu and Z. Zhu, "Nanao multi-terminal VSC-HVDC project for integrating largescale wind generation," in PES General Meeting| Conference \& Exposition, 2014.

[15] Robust Control Toolbox 2015b, The MathWorks Inc., Natick, MA, USA, 2015.

[16] P. Apkarian and D. Noll, "Nonsmooth Hळ synthesis," IEEE Trans. Autom. Control, vol. 51, no. 1, pp. 71-86, Jan. 2006.

[17] P. Apkarian, P. Gahinet, and C. Buhr, "Multi-model, multi-objective tuning of fixed-structure controllers," in Proc. Eur. Control Conf., Strasbourg, France, Jun. 2014, pp. 856-861. 